\title{
Hydrothermal Synthesis of Highly Water-dispersible Anatase Nanoparticles with Large Specific Surface Area and Their Adsorptive Properties
}

\author{
Xueting $\mathrm{HU}^{1, \mathrm{a}}$,Dongyun $\mathrm{ZHANG}^{1, \mathrm{~b}}$, Siqin $\mathrm{ZHAO}^{1,2, \mathrm{c}}$, and Sin Asuha ${ }^{1,2, \mathrm{~d}}$ \\ ${ }^{1}$ Chemistry \& Environment Science College, Inner Mongolia Normal University, Inner Mongolia, 81 \\ Zhaowudalu, Huhhot 010022, China \\ ${ }^{2}$ Key Laboratory of Physics and Chemistry of Functional Materials, Inner Mongolia, 81 Zhaowudalu, \\ Huhhot 010022, China \\ ahxueting922@163.com, ${ }^{\mathrm{b}} \mathrm{z}$ _dongyun123@163.com, ${ }^{\mathrm{c}}$ zhaosq@imnu.edu.cn, ${ }^{\mathrm{d}}$ asuha@imnu.edu.cn
}

\begin{abstract}
Highly water-dispersible and very small $\mathrm{TiO}_{2}$ nanoparticles $(\sim 3$ $\mathrm{nm}$ anatase) with large specific surface area have been synthesized by hydrolysis and hydrothermal reactions of titanium butoxide and used for the removal of three azo dyes (Congo red, orange II, and methyl orange) with different molecular structure from simulated wastewaters. The synthesized $\mathrm{TiO}_{2}$ nanoparticles are well dispersed in water with large specific surface area up to $417 \mathrm{~m}^{2} \mathrm{~g}^{-1}$. Adsorption experiments demonstrated that the water-dispersible $\mathrm{TiO}_{2}$ nanoparticles possess excellent adsorption capacities for Congo red, orange II, and methyl orange, which could be attributed to their good water-dispersibility and large specific surface area.
\end{abstract}

\section{Introduction}

Owing to their excellent physical and chemical properties, titanium dioxide $\left(\mathrm{TiO}_{2}\right)$ nanoparticles (NPs ) have shown great potential in various applications such as photocatalysts, pigments, solar cells, water photolysis for hydrogen production, ultraviolet blockers and adsorbents [1-5]. For many applications, high quality anatase NPs with large specific surface area are required to satisfy individual demands. Additionally, for water treatment applications, the $\mathrm{TiO}_{2}$ NPs also required to have good dispersivity in water since highly water-dispersible properties can greatly increase the contact area and contact opportunity between the solid and contaminant ions or molecules. In general, the surface chemical properties of NPs largely depend on their synthetic routes. Therefore, various preparation methods have been developed to produce $\mathrm{TiO}_{2} \mathrm{NPs}$, such as sol-gel process,

* Corresponding author:hxueting922@163.com 
hydrothermal method, solvothermal method, and electrochemical deposition [6]. Among these, the sol-gel method attracts much attention and is extensively used for the synthesis of $\mathrm{TiO}_{2}$ NPs owing to its convenience and low cost. However, the NPs synthesized by conventional sol-gel method suffer from problems of aggregation that is driven by lowering the surface energy of the system. Consequently, as-obtained precipitate is not able to be re-dispersed in water to form stable colloidal solution. For this reason, in recent years, some modified sol-gel methods have been developed, and it has been demonstrated that water-dispersible $\mathrm{TiO}_{2} \mathrm{NPs}$ can be prepared via controlling particle size and preventing particle agglomeration [7].

In the present work, we report the synthesis of water-dispersible $\mathrm{TiO}_{2} \mathrm{NPs}$ with a large specific surface area using a combination of hydrolysis and hydrothermal reactions of titanium butoxide (TBOT). This method is initiated by the hydrolysis of TBOT in the presence of excess water and moderate amount of nitric acid. Subsequently, the dehydration of $-\mathrm{TiOH}$ groups obtained in the previous step was activated under hydrothermal conditions to produce $\mathrm{TiO}_{2} \mathrm{NPs}$. The facile method adopted in this study was found to be an efficient technique for the synthesis of water-dispersible $\mathrm{TiO}_{2} \mathrm{NPs}$ with a large specific surface area up to $417 \mathrm{~m}^{2} \mathrm{~g}^{-1}$. To our best knowledge, there is no any reported $\mathrm{TiO}_{2} \mathrm{NPs}$ with such a higher specific surface area. In addition, for the first time, we report the enhanced adsorption of Congo red (CR), orange II (O II), and methyl orange (MO) on the synthesized $\mathrm{TiO}_{2} \mathrm{NPs}$.

\section{Materials and Methods}

\subsection{Materials}

Tetrabutyl titanate (TBOT, $\geq 98 \%$ ) was used as a source of $\mathrm{Ti}^{4+}$ and procured from Tianjin Beilian Fine Chemical Reagents Company. Nitric acid (68\%) and absolute ethanol $(\geq 99 \%)$ were purchased from Beijing Chemical Reagents Company and used as a catalyst and solvent, respectively. Different dyes (99\%) used in this study were purchased from China Medicine Company.

\subsection{Synthesis of TiO2 NPs}

$\mathrm{TiO}_{2}$ NPs were synthesized by a combination of hydrolysis and hydrothermal reactions of TBOT. $3.0 \mathrm{~mL}$ of TBOT was mixed with $5.0 \mathrm{~mL}$ of ethanol and certain amount $(1.0-9.0 \mathrm{~mL})$ of $2.0 \mathrm{M} \mathrm{HNO}_{3}$ to form a transparent solution. Subsequently, $24.0 \mathrm{~mL}$ of deionized water was added dropwise to the TBOT- $\mathrm{C}_{2} \mathrm{H}_{5} \mathrm{OH}-\mathrm{HNO}_{3}$ solution under constant stirring for $1 \mathrm{~h}$ to obtain homogeneity. The solution thus obtained was transferred to a Teflon-lined stainless autoclave of capacity $50-\mathrm{mL}$, followed by heating in a conventional oven at $110^{\circ} \mathrm{C}$ for $3 \mathrm{~h}$. The resultant precipitate was washed several times in ethanol to remove any unreacted reactants and separated from the solution by high-speed centrifugation. Finally, the precipitate was dried in an oven at $80^{\circ} \mathrm{C}$, resulting in the formation of a white powder with low density. In this study, we varied the amount of $\mathrm{HNO}_{3}$ to analyze the effect of concentration of acid on the properties of resulting $\mathrm{TiO}_{2} \mathrm{NPs}$. The samples obtained with 0 , 1, 3, 5, 7, and $9 \mathrm{~mL} 2.0 \mathrm{M} \mathrm{HNO}_{3}$ are hereafter designated as T-acid-0, T-acid-1, T-acid-3, T-acid-5, T-acid-7, and T-acid-9, respectively.

\subsection{Characterization}

$\mathrm{TiO}_{2}$ NPs synthesized as discussed above were characterized by several techniques. X-ray diffraction patterns (XRD) of the $\mathrm{TiO}_{2} \mathrm{NPs}$ were obtained by a Rigaku D/Max-Ultima IV diffractometer using $\mathrm{CuK} \alpha$ radiation. The specific surface area of the resultant $\mathrm{TiO}_{2} \mathrm{NPs}$ was measured with a Micrometrics ASAP2020 Analyzer (Brunauer-Emmett-Teller, BET 
method). Transmission electron micrographs (TEM) and selected area electron diffraction (SAED) were recorded using a FEI TECNAI G2F20 transmission electron microscope. Thermogravimetric analysis (TGA) was carried out in air, at a heating rate of $5^{\circ} \mathrm{C} \mathrm{min}^{-1}$ from room temperature to $800^{\circ} \mathrm{C}$, using a Shimadzu DTG- $60 \mathrm{H}$ apparatus.

\subsection{Azo dyes adsorption}

For adsorption experiments, the sample T-acid-1 was used as adsorbent since it possessed the highest specific surface area among the all synthesized samples; and, each adsorption experiment was conducted by adding fixed amount of $\mathrm{TiO}_{2} \mathrm{NPs}(30 \mathrm{mg})$ to $20 \mathrm{~mL}$ of dye solution. All adsorption experiments were carried out at room temperature $\left(20^{\circ} \mathrm{C}\right)$. The mixture was agitated in a shaking water bath at a constant speed of $300 \mathrm{rpm}$ at room temperature for a certain time. After the adsorption processes, solution and $\mathrm{TiO}_{2} \mathrm{NPs}$ were separated by high-speed centrifugation and the concentration of dye in the supernatant was immediately determined using a Shimadzu UV-Vis 2550 spectrophotometer at their respective absorbance maxima.

\section{Results and Discussion}

The XRD patterns depict the formation of $\mathrm{TiO}_{2}$ with main diffraction peaks at $2 \theta=25.1$, $37.8,48.0,54.6$, and 63.4, corresponding to the crystal planes of (101), (004), (200), (105), and (204), respectively (Fig. 1). These peaks are consistent with the JCPDS file (e.g., No.71-1167) of anatase. The average crystallite sizes (A.C.S) of all samples calculated from the half-width of the diffraction lines using the Scherrer's equation were in the range 3.1-3.7 $\mathrm{nm}$, showing that relatively small anatase NPs could be obtained by this method. We found that the amount of $\mathrm{HNO}_{3}$ has no significant influence on $\mathrm{TiO}_{2} \mathrm{NPs}$ crystallite sizes (Table 1). Fig. 2a shows the photographs of $\mathrm{TiO}_{2} \mathrm{NP}$ aqueous solutions with different concentration prepared from the sample T-acid-1. The synthesized $\mathrm{TiO}_{2} \mathrm{NPs}$ could be readily dispersed in water, with the solution remaining stable after more than several months, due mainly to the small size and hydrophilic properties of the NPs. As can be seen in TEM image (Fig. 2b), the as-synthesized $\mathrm{TiO}_{2} \mathrm{NPs}$ are highly crystalline and their average crystallite size is less than 5 $\mathrm{nm}$, approximately consistent with the result obtained by XRD. The specific surface area of the final products was studied by nitrogen adsorption-desorption measurements. The synthesized $\mathrm{TiO}_{2} \mathrm{NPs}$ exhibit very large BET specific surface area $\left(S_{\mathrm{BET}}\right)$, i.e., up to $417 \mathrm{~m}^{2}$ $\mathrm{g}^{-1}$ (Table 1). This value is significantly larger than those $\left(200-256 \mathrm{~m}^{2} \mathrm{~g}^{-1}\right)$ [8-10] of water-dispersible $\mathrm{TiO}_{2}$ NPs synthesized via various methods, which is most likely due to the strategy using a mild synthesis optimized to produce small particles. From the BET analysis of synthesized samples, the amount of $\mathrm{HNO}_{3}$ used in the synthesis reaction was found to have a strong influence on the $S_{\mathrm{BET}}$ of resultant $\mathrm{TiO}_{2} \mathrm{NPs}$. The $S_{\mathrm{BET}}$ of samples T-acid-1, T-acid-3, T-acid-5, T-acid-7, and T-acid-9 were 417, 337, 315, 307, and $261 \mathrm{~m}^{2} \mathrm{~g}^{-1}$, respectively, indicating that the $S_{\mathrm{BET}}$ decreased with the increase of $\mathrm{HNO}_{3}$ amount. This phenomenon has also been reported by other researchers [11, 12], and it can be attributed to a decrease in the cross-linking level. Owing to its large surface large specific surface area and high dispersibility, the present $\mathrm{TiO}_{2}$ NPs are expected to be useful in water treatment; therefore, they were further used to remove azo dyes from simulated wastewater in this study. Fig. 3 shows the adsorption rate curves of CR, O II, and $\mathrm{MO}$ on the $\mathrm{TiO}_{2} \mathrm{NPs}$. The adsorption rates of these dyes were so fast that no data point could be measured in the period from 0 to $5 \mathrm{~min}$, and more than $80 \%$ of these dyes could be removed within $30 \mathrm{~min}$. The highly water-dispersible properties of $\mathrm{TiO}_{2} \mathrm{NPs}$ can greatly increase the contact area and contact 
opportunity between $\mathrm{TiO}_{2} \mathrm{NPs}$ and dye molecules, leading to the high adsorption rate of dyes. The adsorption of different dyes on $\mathrm{TiO}_{2} \mathrm{NPs}$ could reach equilibrium within $40 \mathrm{~min}$.

Table 1.Textural Properties Of Synthesized Samples

\begin{tabular}{|l|c|c|}
\hline Sample & $\mathrm{S}_{\mathrm{BET}}\left(\mathrm{m}^{2} \mathrm{~g}^{-1}\right)$ & A.C.S (nm) \\
\hline T-acid-0 & 263 & 3.7 \\
\hline T-acid-1 & 417 & 3.1 \\
\hline T-acid-3 & 337 & 3.2 \\
\hline T-acid-5 & 315 & 3.2 \\
\hline T-acid-7 & 307 & 3.5 \\
\hline T-acid-9 & 307 & \\
\hline
\end{tabular}

Figure 1. XRD patterns of the synthesed samples.

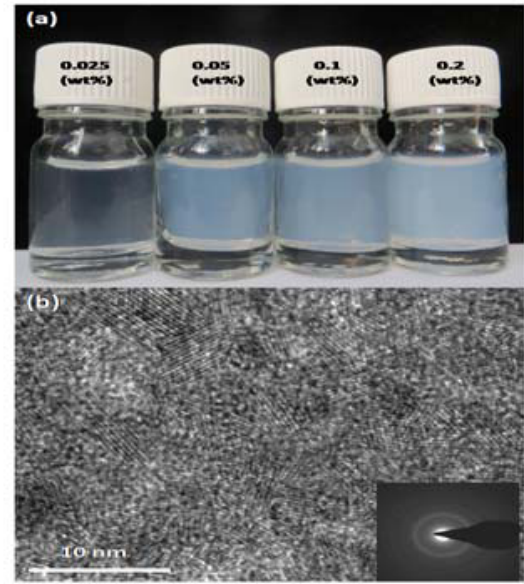

Figure 2. (a) Photographs of the $\mathrm{TiO}_{2}$ NPs aqueous dispersions with different concentrations prepared from the sample T-acid-1; (b) TEM image and SAED pattern (inset) of the sample T-acid-1. 


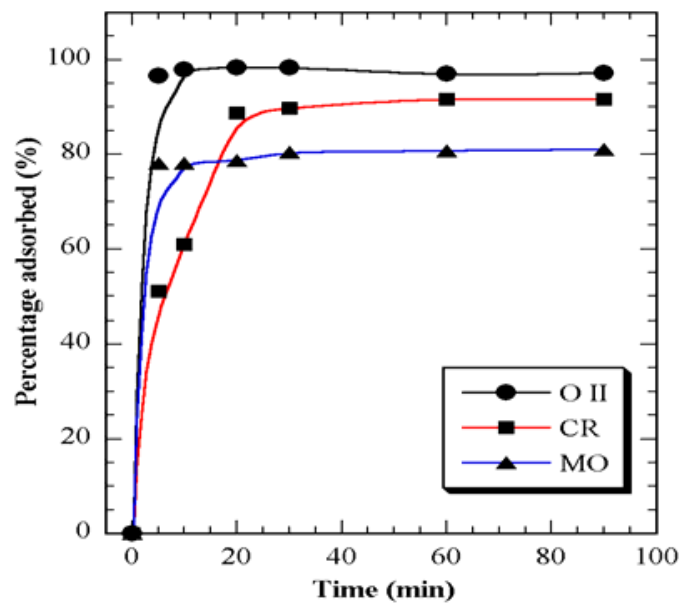

Figure 3. Adsorption rate curves for $\mathrm{CR}, \mathrm{O}$ II and MO.

\section{Summary}

Highly water-dispersible $\mathrm{TiO}_{2}$ NPs are successfully synthesized using a combination of hydrolysis and hydrothermal reactions of titanium butoxide (TBOT). The obtained $\mathrm{TiO}_{2}$ NPs are composed of anatase with average size of $\sim 3 \mathrm{~nm}$ and possess a high surface area $\left(>400 \mathrm{~m}^{2} \mathrm{~g}^{-1}\right)$. Owing to these excellent properties, the $\mathrm{TiO}_{2} \mathrm{NPs}$ show high adsorptive removal abilities for O II, CR, and MO. The adsorption of the three dyes on $\mathrm{TiO}_{2} \mathrm{NPs}_{\text {could }}$ reach equilibrium within $40 \mathrm{~min}$.

\section{Acknowledgments}

This work was supported by National Natural Science Foundation of China (Grant No. 21267016 and 21367020).

\section{References}

1. P. Roy, S. Berger, P. Schmuki, $\mathrm{TiO}_{2}$ nanotubes: Synthesis and applications, Angew. Chem. Int. Ed. 50 (2011) 2904-2939.

2. M. N. Chong, B. Jin, C. W. K. Chow, C. Saint, Recent developments in photocatalytic water treatment technology: A review, Water Res. 44 (2010) 2997-3027.

3. C. Tian, S. Huang, Y. Yang, Anatase $\mathrm{TiO}_{2}$ white pigment production from unenriched industrial titanyl sulfate solution via short sulfate process, Dyes Pigments 96 (2013) 609-613.

4. A. J. Frank, N. Kopidakis, J. V. D. Laqemaat, Electrons in nanostructured $\mathrm{TiO}_{2}$ solar cells: Transport, recombination and photovoltaic properties, Coordin. Chem. Rev. 248 (2004) 1165-1179.

5. F. E. Osterloh, Inorganic materials as catalysts for photochemical splitting of water, Chem. Mater. 20 (2008) 35-54.

6. M. A. Behnajady, H. Eskandarloo, N. Modirshahla, M. Shokri, Investigation of the effect of sol-gel synthesis variables on structural and photocatalytic properties of $\mathrm{TiO}_{2}$ nanoparticles, Desalination 278 (2011) 10-17. 
7. P. Wang, D. Wang, H. Li, T. Xie, H. Wang, Z. Du, A facile solution-phase synthesis of high quality water-soluble anatase $\mathrm{TiO}_{2}$ nanocrystals, J. Colloid Interface Sci. 314 (2007) 337-340.

8. J. Jing, J. Feng, W. Li, W. W. Yu, Low-temperature synthesis of water-dispersible anatase titanium dioxide nanoparticles for photocatalysis, J. Colloid Interface Sci. 396 (2013) 90-94.

9. Y. Wang, F. Duo, S. Peng, F. Jia, C. Fan, Potassium iodate assisted synthesis of titanium dioxide nanoparticles with superior water-dispersibility, J. Colloid Interface Sci. 430 (2014) 31-39.

10. N. Watanabe, T. Kaneko, Y. Uchimaru, S. Yanagida, A. Yasumori, Y. Sugahara, Preparation of water-dispersible $\mathrm{TiO}_{2}$ nanoparticles from titanium tetrachloride using urea hydrogen peroxide as an oxygen donor, CrystEngComm 15 (2013) 10533-10540.

11. K. M. S. Khalil, T. Baird, M. I. Zaki, A. A. El-Samahy, A. M. Awad, Synthesis and characterization of catalytic titanias via hydrolysis of titanium(IV) isopropoxide, Colloid Surf. A 132 (1998) 31-44.

12. N. Phonthammachai, T. Chairassameewong, E. Gulari, A.M. Jamieson, S. Wongkasemjit, Structural and rheological aspect of mesoporous nanocrystalline $\mathrm{TiO}_{2}$ synthesized via sol-gel process, Micropor. Mesopor. Mater. 66 (2003) 261-271. 